\title{
Steroid Hormone Levels in the Peripartum Period - Differences Caused by Fetal Sex and Delivery Type
}

\author{
K. ADAMCOVÁ ${ }^{1}$, L. KOLÁTOROVÁ ${ }^{2}$, T. ŠKODOVÁ ${ }^{2}$, M. ŠIMKOVÁ ${ }^{2}$, A. PAŘíZEK ${ }^{1}$, \\ L. STÁRKA ${ }^{2}$, M. DUŠKOVÁ ${ }^{2}$
}

${ }^{1}$ Department of Obstetrics and Gynecology of the First Faculty of Medicine and General Teaching Hospital, Prague, Czech Republic, ${ }^{2}$ Institute of Endocrinology, Prague, Czech Republic

Received August 1, 2018

Accepted September 5, 2018

\section{Summary}

Progesterone, estrogens, androgens and glucocorticoids all play important roles during pregnancy, from implantation to delivery. Focusing on selected steroid hormones in the peripartum period, we defined reference ranges measured using LS-MS/MS, and assessed relationships with maternal age, pregnancy weight gain, delivery type, and fetal sex. Samples were taken from 142 healthy women with physiological gravidity at the $37^{\text {th }}$ week, during the first period of labor, and from newborn mixed cord blood. We found higher cortisol and $17-\mathrm{OH}$-pregnenolone plasma levels in mothers at the $37^{\text {th }}$ week that carried male fetuses $(p=0.03)$, but no significant differences in any studied hormones in newborns of different sex. Neither maternal age nor weight gain nor newborn birth weight had any relationships to any of the studied hormones. However, there were differences depending on vaginal versus planned cesarean section deliveries. In women carrying a male fetus we found significantly higher levels of 17-OH-pregnenolone, progesterone, cortisol, corticosterone and significantly lower levels of estradiol in those undergoing spontaneous vaginal delivery. However, we found no significant differences in the cord blood of newborn males from either delivery type. We established reference ranges for our analysis methods, which should be useful for further studies as well as in standard clinical practice.

\section{Key words}

Newborn • Delivery • Steroids • Physiological range • Cord blood - Sex

\section{Corresponding author}

M. Dušková, Institute of Endocrinology, Národní 8, 11694 Prague 1, Czech Republic. E-mail: mduskova@endo.cz

\section{Introduction}

The production and activities of steroid hormones during pregnancy have many interesting aspects. Their synthesis and metabolism are the result of complex metabolic pathways encompassing activities in the fetus, placenta, and mother. Some fundamental enzymes of steroidogenesis are absent in the fetus (e.g. 3 $\beta$-hydroxysteroid dehydrogenase, aromatase) and in the placenta (e.g. 16 $\alpha$-hydroxylase, 17 $\alpha$-hydroxylase). In the fetus, there are high activities of the conversion of acetate to cholesterol, the transformation of pregnene to androstenes, and the 16-hydroxylation of DHEA, which is essential in the production of estriol. All these transformations are absent in the placenta, but the placenta can metabolize cholesterol to C21-steroids, convert 5-ene to 4-ene steroids, and has a high capacity to aromatize C19 precursors. Thus together the fetus and the placenta are able to produce all necessary steroid hormones (Pasqualini and Chetrite 2016).

The production of steroids in the human fetus is localized mainly in the adrenal glands, with primitive adrenocortical cells appearing in the fourth week of gestation. Two zones can be detected by the eighth week, the fetal zone and the definitive zone. The fetal adrenals grow very quickly, reaching about $6-8 \mathrm{~g}$ by the end of pregnancy, of which $80 \%$ is comprised of the fetal zone that disappears during the first few months after birth; the definitive zone differentiates into the well-known regions: the fascicular, reticular, and glomerular (Pasqualini and Chetrite 2016).

The production of some steroid hormones 
increases markedly during pregnancy (e.g. estriol increases by $500-1,000 \mathrm{x}$ compared to non-pregnant women). In addition to changes to steroids as a result of the course of pregnancy, there are various factors that influence their levels (age, smoking, complications of pregnancy, treatments with glucocorticoids, etc.), and which can play a role in a wide range of disorders in both the intrauterine but also later life stages of the child (Kuijper et al. 2015, Adamcová et al. 2017). The role of steroid level changes in various disorders has been described from experimental model animals, but such results are difficult to apply to pregnancy in humans, as shown by the study of Heusnner et al. (2016). Authors demonstrate differences between activities of placental enzymes (11ß-hydroxysteroid dehydrogenase type 1 and 2), which protect fetus from high level of glucocorticoids in human and rat placenta. These differences between species make impossible the transmission of results (Heusnner et al. 2016).

Another way to analyze relationships between steroid changes in utero and various pathologies are associative studies. These are complicated by the fact that an association does not prove causality, but they can lead to new hypotheses, making such studies important. To understand the complex relationships and functions of steroids, it is at first necessary to have a good understanding of their changes due to physiology. Changes described by associative studies may lead to new hypotheses, but they may also be merely accidental findings within normal physiological variation. Precise laboratory analyses are therefore of fundamental importance, respecting detection limits and the correct setting of reference ranges for a given analyte (Dušková et al. 2018), so that associations do not arise just because of inaccurate measurements.

The aim of this study was to measure selected steroid hormones in the peripartum period, define their reference ranges for the given analytical method, and assess relationships to maternal age, the growth of hormones during pregnancy, delivery type, and fetal sex.

\section{Methods}

\section{Study group}

The study included 142 healthy pregnant Czech women with physiological courses of gravidity. Exclusion criteria were any addiction in their medical history, the use of medications influencing steroidogenesis, gestational diabetes, hypertension, thyreopathy, pregnancy complications (hyperemesis, bleeding, endometriosis, risk of preterm labor), intrauterine fetal growth restriction, and a multiple pregnancy. All participants signed informed consent. The study was approved by the Ethical Committee of the General Faculty Hospital (protocol no. 114/15), and followed the Declaration of Helsinki (2000) of the World Medical Association.

The women were examined in the $37^{\text {th }}$ week of pregnancy, when they filled out an anonymous questionnaire on their age, height, weight, gravidity/ parity, pregnancy complications, and socioeconomic status. At childbirth the sex and type of delivery were noted. Births were classified as either spontaneous or by cesarean section, and those by cesarean section further divided into planned or acute. Planned cesarean sections were those that were elective, i.e. operations whose indications appeared before the onset of labor, while acute or secondary cesarean sections were those that were selective, with indications that could not be predicted. In current obstetrics the following indications are most common: fetal hypoxia, cervical-corporal dystocia, a prior cesarean section, and breech positioning. These were also the most common indications in our study, and the ratio of mothers undergoing cesarean sections in our study ( 28 out of 142 , or $27 \%$ ) was similar to the national average $(28 \%)$.

At the $37^{\text {th }}$ week of pregnancy a sample of venous blood was taken from the mother's cubital vein between 8-10 A.M. Another sample was taken during the first stage of labor, and then from mixed cord blood. Due to the technical difficulty in sampling arterial versus venous cord blood, and in light of our previous results comparing such separate sampling (Pašková et al. 2014), we chose to sample mixed cord blood. Blood was collected into two $4 \mathrm{ml}$ Vacuette tubes (plastic tubes for collecting coagulating venous blood with a coagulation activator and separation gel). Serum was obtained by centrifugation for $5 \mathrm{~min}$ at $2,000 \mathrm{~g}$ at $4{ }^{\circ} \mathrm{C}$, and then stored at $-20{ }^{\circ} \mathrm{C}$.

To calculate reference ranges, we used all samples from the $37^{\text {th }}$ week, 81 of which were from women carrying girls, and 61 from those carrying boys. Characteristics of pregnant women are present in the Table 1. Samples from the first stage of labor and from cord blood were only taken from women that underwent spontaneous childbirth (59 girls/45 boys). Characteristics of neonate are present in the Table 2 . There were too few samples from planned cesarean sections to calculate 
reference ranges, so those samples were only used to compare steroids between women carrying boys undergoing spontaneous births (45 samples) and planned cesarean sections (12 samples). There were not enough samples from mothers undergoing acute cesarean sections or from mothers carrying girls undergoing cesarean sections (planned and acute), so these samples were not used in subsequent analyses. During childbirth, technical reasons (not medical complications) prevented 8 samples to be taken from women carrying girls and one carrying a boy. In these cases cord blood was not removed.

\section{Measurement of analytes}

Estrone (E1), estradiol (E2) and estriol (E3) were quantified using a previously published LC-MS/MS method (Vitku et al. 2015). All other steroids (cortisol, cortisone, dehydroepiandrosterone (DHEA), $7 \alpha$-hydroxydehydroepiandrosterone ( $7 \alpha-\mathrm{OH}-\mathrm{DHEA}), 7 \beta$-hydroxydehydroepiandrosterone (7 $\beta$-OH-DHEA), 7-oxo-dehydroepiandrosterone (7-oxo-DHEA), pregnenolone, $17 \alpha$-hydroxy-pregnenolone (17-OH-pregnenolone), testosterone, androstenedione, progesterone, 17-OH-progesterone, corticosterone) were determined using other LC-MS/MS validated methods (Sosvorova et al. 2015a, Sosvorova et al. 2015b, Vitku et al. 2016). Since two samples were taken from at each collection, analyses were repeated to be able to correlate the precision of quantification.

\section{Statistical analysis}

In cases where both the standardized skewness and standardized kurtosis values of the data were within the range expected $( \pm 2)$, the t-test to compare means was used to explore the differences between steroid levels in women carrying female and male fetuses at the $37^{\text {th }}$ week of pregnancy and during first stage of labor, between women undergoing spontaneous birth and caesarean sections with male fetuses in the first period of labor, and in cord blood. In cases where standardized skewness and kurtosis values of the data were outside the range expected $( \pm 2)$, a non-parametric analogue of the t-test, the Kolmogorov-Smirnov test, was used to explore these differences. This test is performed by computing the maximum distance between the cumulative distributions of the two samples.

A simple regression analysis was used to examine the repeated sample measurement. Reference ranges were calculated based on the $2.5-97.5^{\text {th }}$ percentiles of the measured data.
The statistical software Statgraphics Centurion XVI from Statpoint Inc. (Warrenton, VA, USA) was used for all data processing.

Partial correlations between mother age, pregnancy weight gain, birth weight and steroid levels were assessed in NCSS 2007 (Kaysville, UT, USA).

\section{Results}

In this study we focused on 16 steroids, which we measured in mothers at the $37^{\text {th }}$ week of pregnancy, during the first stage of labor, and in newborn cord blood. We established reference ranges for individual steroids for measurements using our LC-MS/MS methods (Table 3). In order to obtain sufficient numbers of sample for calculating reference ranges, samples from the first stage of labor and from newborns were only used from spontaneous deliveries. Measurement of repeated sampling was performed, with excellent correlations between samples (from 81-99\%), demonstrating the precision of these methods for all analyzed steroids.

In addition, we analyzed relationships between the studied steroids and selected parameters, which are described in the following text with all significant differences, but we do not show all these data in the tables. We found no significant relationships between maternal age and any studied steroid. Weight gain, either to the $37^{\text {th }}$ week or throughout the pregnancy, also did not correlate with any of the steroids tested. Similarly, newborn birth weight had no relationship to hormone levels in physiological deliveries.

In maternal blood at the $37^{\text {th }}$ week, we did find significant differences between steroids depending on the sex of the fetus. Cortisol was higher in mothers carrying sons $(p=0.03)$, while 17-OH-pregnenolone was higher in mothers carrying daughters $(\mathrm{p}=0.0038)$. Progesterone was non-significantly higher in women carrying daughters $(p=0.082)$. In newborns, we found no significant differences between the studied steroids and sex. As mentioned above, only results from spontaneous vaginal births were analyzed to obtain sufficient numbers.

We also compared steroid levels between types of delivery: vaginal versus planned cesarean section. Unfortunately, there were insufficient samples from women undergoing acute cesarean sections and who were carrying daughters to analyze, so only those carrying sons were included. Of the women carrying sons, we found significantly higher levels of 17-OH-pregnenolone $(p=0.012)$, progesterone $(p=0.022)$, cortisol $(p=0.0022)$, 


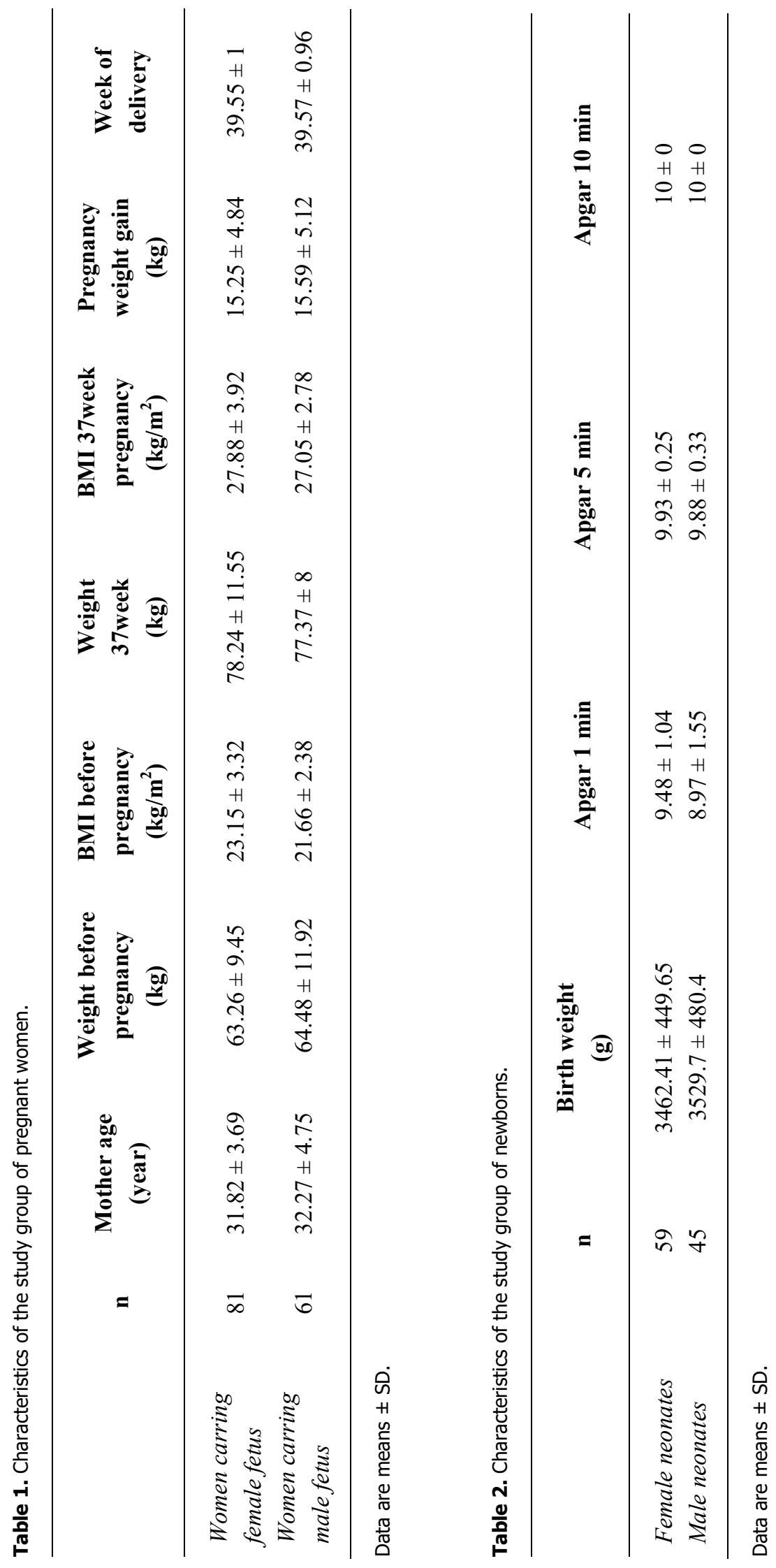




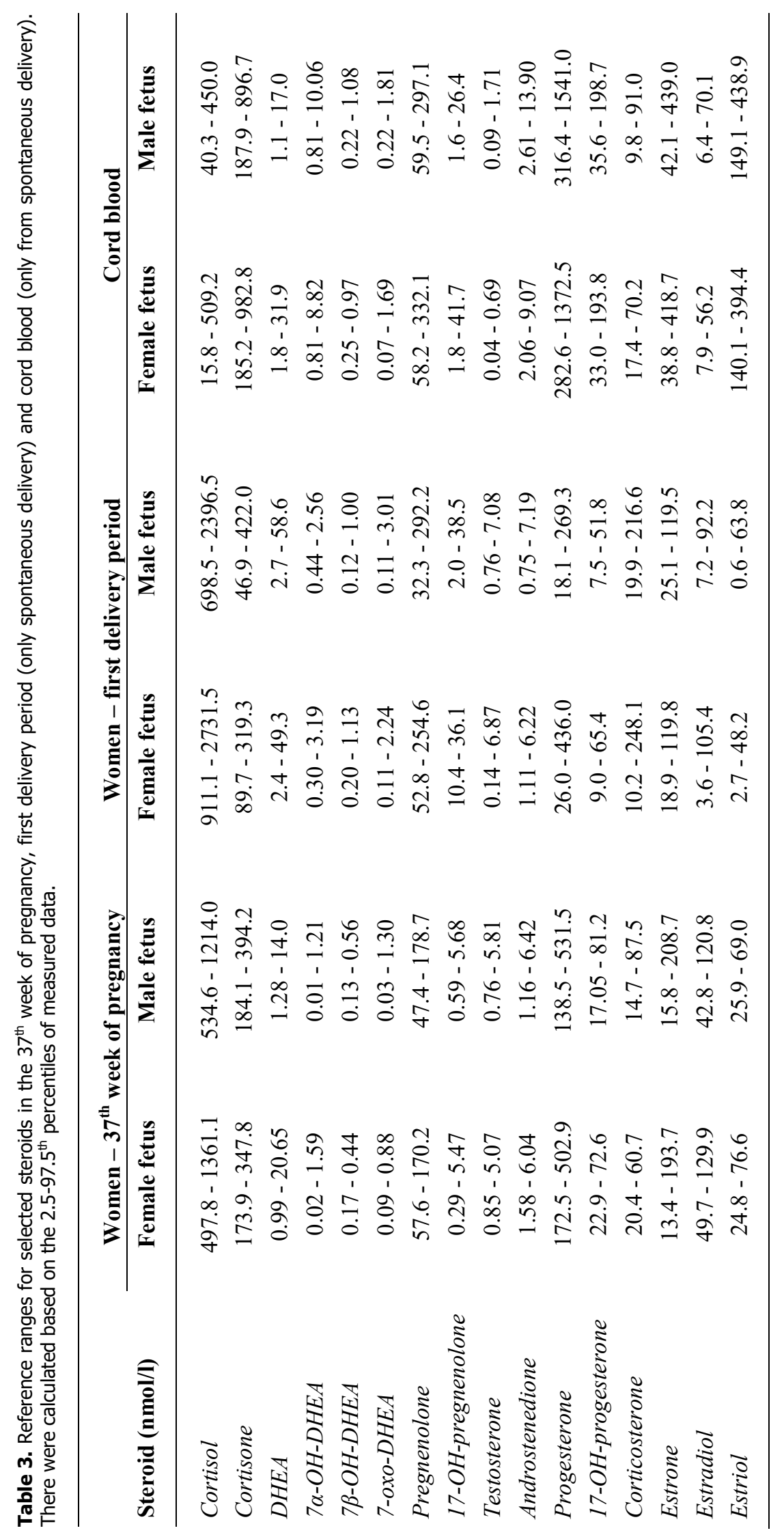


and corticosterone $(\mathrm{p}=0.0078)$, and insignificantly higher levels of 17-OH-progesterone $(p=0.068)$, plus significantly lower levels of estradiol $(p=0.0017)$ in women undergoing spontaneous vaginal birth compared to those with planned cesarean section. In the cord blood of newborn sons, we found no significant differences between those delivered vaginally and by cesarean section, with only borderline differences for progesterone $(p=0.057)$ and androstenedione $(p=0.065)$.

\section{Discussion}

During pregnancy, from implantation to childbirth, progesterone, estrogens, androgens and glucocorticoids all play important roles. In order to follow relationships between these hormones, their physiological levels must be determined. In light of the problems with measuring steroid hormones arising from the difficulties in steroid analytics (Dušková et al. 2017), when new methods are introduced it is necessary to determine reference ranges for that given method. Our laboratory has a long tradition in measuring steroid hormones during pregnancy and the peripartum period using gas chromatography with mass spectrometry, both focusing on physiological relationships (Hill et al. 2010a, Hill et al. 2010b, Hill et al. 2010c, Pašková et al. 2014), but also on associations with pathological states such as postpartum depression, intrahepatic cholestasis, and gestational diabetes (Pařízek et al. 2014, Pařízek et al. 2015, Pařízek et al. 2016). When introducing new methods based on LC MS/MS we obtained a panel of physiological values during pregnancy and establish reference ranges for these methods. Those results showed excellent reproducibility and are in line with other data from the literature. The analysis method used should always be kept in mind, as it is impossible to compare results from different methodologies (e.g. chromatography vs. immunoanalysis).

Our results here from analyzing the relationships between steroid levels are intriguing. We focused on differences based on fetal sex, which in the literature have been variously described as being lower, higher, or indifferent (Kuijper et al. 2015). We only found significant differences in mothers at the $37^{\text {th }}$ week for cortisol and 17-OH-progenenolone. Our cortisol results are not in line with studies that followed saliva cortisol in the second half of pregnancy, but it must be noted that it is difficult to compare results from saliva and plasma cortisol. Saliva cortisol has been described as being elevated in mothers carrying sons up to the $30^{\text {th }}$ week, and then higher in mothers carrying daughters (DiPietro et al. 2011). In newborns we found no differences in steroids based on sex. Levels were not completely identical, however, so for calculating reference ranges should be treated separately. On the other hand, this lack of differences allows analyses of some changes without regard to sex, if the pathology is not related to the child's sex.

In our study, maternal age did not correlate with steroid levels. Some studies have described higher estrogens (Troisi et al. 2008) and testosterone (Carlsen et al. 2003, Troisi et al. 2008) in younger mothers, but these results are from the first half of pregnancy and using longitudinal monitoring. Those authors speculated on the importance of these differences in relation to the development, for instance, of breast cancer later in life. These associations are interesting, but differences associated with maternal age must be evaluated carefully, since steroid production in pregnancy mainly occurs in the placenta and fetal adrenals, and less so in the mother.

Newborn birth weight showed no relationship to steroid levels in the mothers during pregnancy in our study. However, we only monitored physiological pregnancies, and all newborns had normal birth weight. There have been reports in the literature on relationships between higher androgens in newborns with growth retardation (Carlsen et al. 2006). The weight gain in our study group of mothers was not extremely high or low, and we found no relationships to steroid levels. This could also be the result of this not being a longitudinal study.

This differences we found in steroids between delivery types are very interesting. Steroid levels in planned cesarean sections de facto reflect the steroid spectra at the end of pregnancy, while levels during spontaneous deliveries include the changes brought on by childbirth with the limitation explained below. As expected, we found significantly higher levels of cortisol and corticosterone in the woman undergoing spontaneous delivery, which reflected stress reaction and also mainly the mechanisms initiating childbirth. We found lower estradiol and higher progesterone and 17-OH-pregnenolone in mothers undergoing spontaneous delivery. Surprisingly, no significant differences were found in cord blood.

The mechanisms initiating childbirth are complex, with hormonal changes playing a key role. In spite of many advances and promising hypotheses, 
however, the exact process initiating childbirth in humans is as yet unknown, and results from experimental models are difficult to apply due to different hormone systems among species.

In our study we found higher cortisol and corticosterone levels during spontaneous births, which are in line with data from the literature and the idea that activation of the stress axis plays a role in the initiation of childbirth (Ravanos et al. 2015). In animal models, there is a direct relationship between the initiation of childbirth and increased fetal activity of the hypothalamic-pituitaryadrenal (HPA) axis. The stimulation of cortisol production in fetal adrenals by ACTH 1-2 weeks before birth in these models increases the activities of several placental enzymes that lead to changes in the myometrium and cervix (Mastorakos and Ilias 2003).

CRH has been shown to be important in humans, and has been termed the "placental clock" (McLean et al. 1995). The production of CRH in the placenta increases markedly before birth. CRH acts on many areas: increasing the contractility of the myometrium, stimulating the production of prostaglandins in the fetal membranes and decidua, and stimulating the synthesis of cortisol in the fetal adrenals (McLean and Smith 2001).

Lowered progesterone levels play a role in the initiation of childbirth in rabbits and laboratory rodents, but in humans progesterone levels do not seem to change much, being balanced by changes in the estradiol/ progesterone ratio and by changes at the receptor level (Ravanos et al. 2015). Our results are not fully in agreement with this, but likely rather show changes later during the childbirth process and cannot be linked to the initiation of childbirth.

Comparing changes between spontaneous deliveries and planned cesarean sections may seem to be appropriate for assessing hormonal changes leading to the initiation of childbirth. Unfortunately, however, though they can provide a general outline, such data cannot completely be used in this way. The main problem is that planned cesarean sections are normally performed very close to the due date, when it may be assumed that changes in the hormone spectrum leading to spontaneous childbirth are already underway, and we do not know for certain at which stage of the process our sampling takes place. Longitudinal monitoring studies ending in physiological deliveries are therefore necessary for analyzing changes leading to the initiation of childbirth. Our results showing no relationship of hormonal changes in newborns with different delivery types are in line with this. Interpretations using just comparisons of hormone levels during planned cesarean sections and spontaneous deliveries can thus be misleading. Taking these limitations into account, our data supports the theory that hormonal changes leading to activation of the HPA axis are significant in the mechanisms initiating childbirth and in the birth process itself.

In general, when describing changes to steroids during pregnancy it is necessary to respect their physiology. We found changes in steroid levels in women associated with delivery type, and demonstrated the necessity to analyze steroid changes taking the fetal sex into consideration, even though no differences were found in newborns at birth. We also calculated reference ranges for our analysis methods, which should be useful both in further studies and in routine clinical practice.

\section{Conflict of Interest}

There is no conflict of interest.

\section{Acknowledgements}

The study was supported by the MH CZ - DRO (Institute of Endocrinology - EÚ, 00023761), by grant GAUK 542216 and by the project MH CR 17-30528 A from the Czech Health Research Council.

\section{References}

ADAMCOVA K, KOLATOROVA L, CHLUPACOVA T, SIMKOVA M, JANDIKOVA H, PARIZEK A, STARKA L, DUSKOVA M: Changes to fetal steroidogenesis caused by maternal smoking. Physiol Res 66 (Suppl 3): S375-S386, 2017.

CARLSEN SM, JACOBSEN G, BJERVE KS: Androgen levels in pregnant women decrease with increasing maternal age. Scand J Clin Lab Invest 63: 23-26, 2003.

CARLSEN SM, JACOBSEN G, ROMUNDSTAD P: Maternal testosterone levels during pregnancy are associated with offspring size at birth. Eur J Endocrinol 155: 365-370, 2006.

DiPIETRO JA, COSTIGAN KA, KIVLIGHAN KT, CHEN P, LAUDENSLAGER ML: Maternal salivary cortisol differs by fetal sex during the second half of pregnancy. Psychoneuroendocrinology 36: 588-591, 2011. 
DUŠKOVÁ M, KOLÁTOROVÁ L, STÁRKA L: Androgens in women - critical evaluation of the methods for their determination in diagnostics of endocrine disorders. Physiol Res 67 (Suppl 3): S379-S390, 2018.

HEUSSNER K, RUEBNER M, HUEBNER H, RASCHER W, MENENDEZ-CASTRO C, HARTNER A, FAHLBUSCH FB, RAUH M: Species differences of 11 beta-hydroxysteroid dehydrogenase type 2 function in human and rat term placenta determined via LC-MS/MS. Placenta 37: 79-84, 2016.

HILL M, PARIZEK A, JIRASEK JE, JIRKOVSKA M, VELIKOVA M, DUSKOVA M, KLIMKOVA M, PASKOVA A, ZIZKA Z, GERMANOVA A, KOUCKY M, KALOUSOVA M, STARKA L: Is maternal progesterone actually independent of the fetal steroids? Physiol Res 59: 211-224, 2010a.

HILL M, PAŘíZEK A, KANCHEVA R, DUŠKOVÁ M, VELÍKOVÁ M, KŘǏŽ L, KLÍMKOVÁ M, PAŠKOVÁ A, ŽIŽKA Z, MATUCHA P, MELOUN M, STÁRKA L: Steroid metabolome in plasma from the umbilical artery, umbilical vein, maternal cubital vein and in amniotic fluid in normal and preterm labor. $J$ Steroid Biochem Mol Biol 121: 594-610, 2010b.

HILL M, PAŘíZEK A, VELÍKOVÁ M, KUBÁTOVÁ J, KANCHEVA R, DUŠKOVÁ M, ŠIMU゚NKOVÁ K, KLIMKOVÁ M, PAŠKOVÁ A, ŽIŽKA Z, JIRÁSEK JE, JIRKOVSKÁ M, STÁRKA L: The distribution of placental oxidoreductase isoforms provides different milieus of steroids influencing pregnancy in the maternal and fetal compartment. Horm Mol Biol Clin Invest 4: 581-600, 2010c.

KUIJPER EA, TWISK JW, KORSEN T, CAANEN MR, KUSHNIR MM, ROCKWOOD AL, MEIKLE AW, HOMPES PG, WIT JM, LAMBALK CB: Mid-pregnancy, perinatal, and neonatal reproductive endocrinology: a prospective cohort study in twins and singleton control subjects. Fertil Steril 104: 1527-1534, 2015.

MASTORAKOS G, ILIAS I: Maternal and fetal hypothalamic-pituitary-adrenal axes during pregnancy and postpartum. Ann N Y Acad Sci 997: 136-149, 2003.

MCLEAN M, SMITH R: Corticotrophin-releasing hormone and human parturition. Reproduction 121: 493-501, 2001.

MCLEAN M, BISITS A, DAVIES J, WOODS R, LOWRY P, SMITH R: A placental clock controlling the length of human pregnancy. Nat Med 1: 460-463, 1995.

PASKOVA A, PARIZEK A, HILL M, VELIKOVA M, KUBATOVA J, DUSKOVA M, ADAMCOVA K, KOUCKY M, SIMJAK P, CERNY A, STARKA L: Steroid metabolome in the umbilical cord: is it necessary to differentiate between arterial and venous blood? Physiol Res 63: 115-126, 2014.

PAŘÍZEK A, MIKEŠOVÁ M, JIRÁK R, HILL M, KOUCKÝ M, PAŠKOVÁ A, VELÍKOVÁ M, ADAMCOVÁ K, ŠRÁMKOVÁ M, JANDÍKOVÁ H, DUŠKOVÁ M, STÁRKA L: Steroid hormones in the development of postpartum depression. Physiol Res 63 (Suppl 2): S277-S282, 2014.

PAŘÍZEK A, DUŠKOVÁ M, VÍTEK L, ŠRÁMKOVÁ M, HILL M, ADAMCOVÁ K, ŠIMJÁK P, ČERNÝ A, KORDOVÁ Z, VRÁBLÍKOVÁ H, BOUDOVÁ B, KOUCKÝ M, MALÍČKOVÁ K, STÁRKA L: The role of steroid hormones in the development of intrahepatic cholestasis of pregnancy. Physiol Res 64 (Suppl 2): S203S210, 2015.

PAŘÍZEK A, HILL M, DUŠKOVÁ M, VÍTEK L, VELÍKOVÁ M, KANCHEVA K, ŠIMJÁK P, KOUCKÝ M, KOKRDOVÁ Z, ADAMCOVÁ K, ČERNÝ A, HÁJEK Z, STÁRKA L: A comprehensive evaluation of steroid metabolism in women with intrahepatic cholestasis of pregnancy. PLoS One 11: e0159203, 2016.

PASQUALINI JR, CHETRITE GS: The formation and transformation of hormones in maternal, placental and fetal compartments: biological implications. Horm Mol Biol Clin Investig 27: 11-28, 2016.

RAVANOS K, DAGKLIS T, PETOUSIS S, MARGIOULA-SIARKOU C, PRAPAS Y, PRAPAS N: Factors implicated in the initiation of human parturition in term and preterm labor: a review. Gynecol Endocrinol 31: 679-683, 2015.

SOSVOROVA L, VITKU J, CHLUPACOVA T, MOHAPL M, HAMPL R: Determination of seven selected neuro- and immunomodulatory steroids in human cerebrospinal fluid and plasma using LC-MS/MS. Steroids 98: 1-8, 2015a.

SOSVOROVA L, HILL M, MOHAPL M, VITKU J, HAMPL R: Steroid hormones in prediction of normal pressure hydrocephalus. J Steroid Biochem Mol Biol 152: 124-132, 2015 b.

VITKU J, CHLUPACOVA T, SOSVOROVA L, HAMPL R, HILL M, HERACEK J, BICIKOVA M, STARKA L: Development and validation of LC-MS/MS method for quantification of bisphenol A and estrogens in human plasma and seminal fluid. Talanta 140: 62-67, 2015. 
VITKU J, HERACEK J, SOSVOROVA L, HAMPL R, CHLUPACOVA T, HILL M, SOBOTKA V, BICIKOVA M, STARKA L: Associations of bisphenol A and polychlorinated biphenyls with spermatogenesis and steroidogenesis in two biological fluids from men attending an infertility clinic. Environ Int 89-90: 166-173, 2016.

TROISI R, HOOVER RN, THADHANI R, HSIEH CC, SLUSS P, BALLARD-BARBASH R, POTISCHMAN N: Maternal, prenatal and perinatal characteristics and first trimester maternal serum hormone concentrations. $\mathrm{Br} J$ Cancer 99: 1161-1164, 2008. 